\title{
Multilingualism in Under-resourced Languages for Sustainable Development in Rural Communities
}

\author{
Rachel Ayuk Ojong Diba 8 (D) \\ PhD. Assistant lecturer, Linguistics Department, University of Buea, Cameroon \\ $\square$ Corresponding Author: Rachel Ayuk Ojong Diba, E-mail: ashly4roda@yahoo.com
}

\begin{tabular}{l} 
ARTICLE INFORMATION \\
Received: June 08, 2021 \\
Accepted: July 07, 2021 \\
Volume: 1 \\
Issue: 1 \\
DOI: $10.32996 /$ ijls.2021.1.1.2 \\
\hline KEYWORDS
\end{tabular}

Rural multilingualism, underresourced languages, sustainable development

\section{ABSTRACT}

Cameroon, a central African country, is one of the most linguistically diverse countries in Africa with about 280 living languages (Ethnologue 2020), for an estimated population of 26,727,521 people (Worldometer, 2020). Cameroon is second only to Papua New Guinea in terms of its multiplicity of languages for a relatively small population. Contrary to popular opinion, multilingualism exists even in rural communities; in fact, it is even more intense. In Lower Fungom, an incredibly linguistically diverse rural community in the Northwest region of Cameroon, high rates of individual multilingualism are the norm; it is common to find individuals who use more than seven distinct native languages to navigate through their daily lives. However, this multilingualism is usually neglected as a resource by foreign experts in the transmission of knowledge in linguistically diverse communities such as Lower Fungom. In their attempt to transmit knowledge in almost all ramifications including in the global pursuit of sustainable development, experts foreign to the target community typically focus only on the 'understanding' of their message, meanwhile 'understanding' could be totally inconsequential as far as the acceptance of a people is concerned. Sustainable development with trends away from the (socio-cultural and linguistic) norms of a community would be a complete farce. This paper aims at highlighting two key features indispensable for development to be extended to rural communities in Cameroon and for it to be sustainable. These aspects are the active collaboration with community members to obtain culturally appropriate interpretations and the use of all the languages existing in the community in transmitting knowledge. Data for this paper comprises recorded natural speeches, interviews, and observation notes due to prolonged stays in the area and resultant informal discussions with its indigenes. This study will not only add to the handful of studies on rural multilingualism. It will not also only promote multilingualism that has become an endangered practice, but it will also be a crucial addition to efforts of sustainable development in Cameroon.

\section{Introduction}

Cameroon, a central African country, is one of the most linguistically diverse countries in the world with about 280 living languages (Eberhard, Gary, and Fennig, 2020), for an estimated population of 26,727,521 people (Worldometer, 2020). In fact, it is the ninth most linguistically diverse country in the world (Eberhard, Gary, and Fennig 2020), while in Africa it comes in second place after Nigeria. The over twenty-six million people who live within its $472,422 \mathrm{~km} 2$ speak $4.05 \%$ of the world's languages (Eberhard, Gary, and Fennig 2020) rendering the country second only to Papua New Guinea in terms of its multiplicity of languages for a relatively small population (Atechi, 2011). With its approximately 280 languages, Cameroon is an intensely linguistically diverse country where most people habitually use several languages daily. Multilingualism in Cameroon is more apparent in urban settings only because it is typically studied in such settings. It is erroneously believed that rural areas are largely monolingual. However, contrary to popular beliefs, multilingualism exists even in rural communities; in fact, it is even more intense. In Lower Fungom, an incredibly

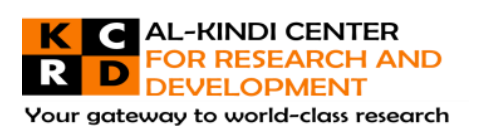

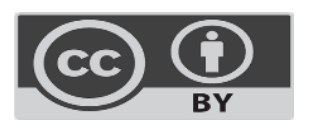

Published by Al-Kindi Center for Research and Development. Copyright (c) the author(s). This open access article is distributed under a Creative Commons Attribution (CC-BY) 4.0 license 
linguistically diverse rural community in the Northwest Region of Cameroon, high rates of individual multilingualism are the norm; it is common to find individuals who use more than seven distinct native languages in their daily lives.

Lower Fungom is located at the northern fringes of the Cameroonian Grassfields and some of its villages are close to the Nigerian border. According to Di Carlo (2016), this is a relatively small region (240 sq km in size, around the same size Amsterdam) characterized by a very hilly landscape, an ecology of forest-savanna mosaic type, and an astonishing degree of language density. $\mathrm{He}$ asserts that in this rural community at least eight different Bantoid languages are spoken in its thirteen villages, yielding a ratio of one language per $30 \mathrm{sq} \mathrm{km}$. Therefore, Lower Fungom, located at the northwestern edge of the Cameroonian Grassfields, an area itself long known for its striking degree of linguistic diversity (Stallcup, 1980: 44) could be one of the linguistically most diverse micro-areas of the African continent (Di Carlo \& Pizziolo, 2012). Worthy of note, high individual multilingualism in Lower Fungom is the norm and has been the norm for several generations. Lüpke (2016) asserts that Lower Fungom is one of the most linguistically diverse regions in the world, with patterns of multilingualism that predate the colonization, the spread of European languages, and the emergence of Pidgin and Creole Languages. In Lower Fungom, multilingualism is scaffolded by the linguistic ideologies of the region; relational identification (the need to be affiliated to people or a group of people) is more prominent than categorical identification (the need to reflect prestige and power) (Di Carlo and Good, 2016). These individuals' linguistic ideologies indexicality (Silverstein, 2003; Di Carlo 2017), oblige them to practice multilingualism; there is a dire need to be multilingual for survival in this rural area. According to Di Carlo (2016), using a given local vernacular is hoped to have direct positive consequences on their personal relationships, such as in obtaining favors or protection and inducing a feeling of trust and unity. In a study on a similar highly linguistically diverse locality in Senegal, Lüpke (2009) revealed that the "majority of Bainouk speakers affirm that the long-established multilingualism in Joola languages and Mandinka is part of their identity, priding themselves on being able to communicate with all major linguistic groups of Casamance [i.e. the region where Bainouk varieties are spoken] and beyond". Similarly, in Lower Fungom it is typical to find individuals who use up to eight distinct local languages in their daily lives (Ojong Diba, 2019). Essene Agwara (2017) affirms that there are no monolinguals in Lower Fungom; at the very least, one would find bilinguals in local languages or in a local language and CPE.

It is typical for these individuals to use multiple languages in the course of their daily activities. Ojong Diba (2019) recounts instances where the natural conversations of certain multilingual individuals revealed them using more than six local languages of Lower Fungom within a period of three and a half hours. (Kulani) uses two distinct languages with two relatives in close proximity on the same topic, see example 2). This is because, in this linguistically diverse locality, linguistic behaviors are highly suggestive and symbolic. Using CPE, for example, suggests a lack of familiarity and trust meanwhile using an interlocutor's native language especially when it is not the speaker's native language, suggests a bond- a relationship.

\section{Problem}

Countries around the world seek to make life better for their people including people in rural environments. Rural development is a key part of the overall structural transformation of a country's economy. Ending poverty and hunger by proposing better agricultural techniques, better farming techniques, and bringing medical care to the rural population are typical aspirations for certain governments. This is typically in a bid to meet the Sustainable Development Goals (SDGs) set up by the UN in 2015. Sustainable development in a rural community, be in the social, economic, or environmental domain would be different from that in an urban community; rural areas have different characteristics than urban areas. Consequently, the challenge is adopting practices that would suit a particular locality. The need for the conscious use of the native language of each village for the transmission of knowledge in linguistically diverse communities such as Lower Fungom is often ignored by foreign experts. In their attempt to transmit knowledge in almost all ramifications including in the global pursuit of sustainable development, experts foreign to the target community typically focus only on the 'understanding' of their message. They focus on communication tout court meanwhile 'understanding' could be totally inconsequential as far as the acceptance of a people is concerned. Understanding a message does not mean that the message will engage the concerned audience. People may understand the words uttered, but they may not make sense of them if the contents are too far removed from their lived realities, their traditions, and what they normally do every day. Sustainable development with trends away from tolerance and celebration of cultural and linguistic diversity in the region where language is [more than anything else] symbolic would be a complete farce.

\section{Aims}

This paper aims at highlighting two key features indispensable for development to be extended to rural communities across Africa and for it to be sustainable. These aspects are the active collaboration with community members to obtain culturally appropriate interpretations and the use of the native language of each village in the community in transmitting knowledge.

\section{Methodology}

Data for this study was collected through the recording of natural conversations of some of the indigenes of Lower Fungom. Three individuals were made to wear audio recorders and microphones in turns. They wore the microphones on their shirts (since these 
were Lavalier microphones) and attached the recorder to their belts. They were taught to switch the audio recorders on and off so that they could continue recording by themselves. After adjusting the necessary parameters (on the recorder) like time, date, and volume, the consultants then wore the microphone and went about their activities, fetching palm wine (for instance) from the forest or attending Njangi meetings. The consultants wore the recorder for a maximum period of three hours, thirty minutes. After collecting the tape recorder, an appointment was made for another day during which we would listen to the data and analyze it.

The paper is also based on data obtained via unstructured observation due to prolonged stays in the area and resultant informal discussions with its indigenes. In the course of doing another study in Lower Fungom, there was a need to be immersed in the community with the indigenes, resulting in unstructured observation, which led to the understanding of several phenomena including the shortcomings of rejecting the socio-cultural and linguistic status quo of the different communities that Lower Fungom comprises.

This ethnographic study that started in 2015 and ended in 2020 allowed for the willingness and ability of respondents to report accurately. The biasing effect of the presence of recorders and formal interviewing was eliminated. Giving the fact that I had lived in the community for a long time, informal or casual questioning did not appear like I was undertaking any study. They appeared as I was interacting with them as any other person would. This data for this participatory study thus reflects the absolute reality of the people I observed. The questions I posed were regarding the attitude and motivation (or lack there-of) of the indigenes of Lower Fungom towards certain practices and notes

were taken as soon as I retired to my residence. These notes contained:

1) The date of observation;

2) A list of participants;

3) A description of the setting and event;

4) Detailed descriptions of the actions of those being observed;

5) Who to meet to reflect upon the actions and event observed.

Inter alia, the above five items constituted the guiding variables on our observation protocol.

\section{Data}

The data presented in this paper are evidence of the conscientiousness involved in linguistic practices in Lower Fungom. I present this practice to illustrate how paramount using the appropriate code is in this region, failure to emulate such linguistic practices when in Lower Funogm is likely to yield negative results. The practice illustrated here contrasts with those of foreign experts who venture into this region with the goal of offering its inhabitants a better lifestyle.

\section{Exhibit 1}

This conversation occurred in my presence, in one of my consultants called Jael's home in Abar, between she and a potential buyer who was not from Lower Fungom but had been residing in this area for a long time. The buyer was an elderly woman of the Aku family (the Aku are a kind of Funlani). The people were famous for a change with respect to the phonology and morphology of CPE. Jael, cognizant of the symbolic nature of language among her people, extend it to someone who did not belong to that community. As typical of her (as observed in a previous qualitative study-Ojong Diba, 2020), following her usual practice of code regimentation (see Ojong Diba 2020), she abandoned the regular variety of CPE which she was using with me prior to the customer's arrival and picked up the variety of CPE spoken by the Aku people. Her goal was that her linguistic practice would resemble that of her potential customer. She would have used the customer's language if she were from any of the villages of Lower Fungom but she was not, hence the use of CPE. While Jael was serving her customer, a passer-by (one of her neighbors in her family compound in Buu) called her up and greeted her in Buu and Jael responded in Buu (seen in the text in bold).

The above is seen in the excerpt below from a video-recorded conversation that I did for a previous study. J represents Jael and $A$ represents the Aku customer. So, J-A means Jael is speaking to the Aku customer while A-J means the Aku is peaking to Jael.
J-A bikin own e dey, for newborn bikin
Regular variety pikin e own dey, for newborn pikin
Free trans There are for babies too, newborns.
J-A na ya own bebe e own that, I don bring only small, this one na for that one so, big one for this one.
Regular variety na ya own bebe e own that, I don bring only small, this one na for that one so, a big one for this one
Free trans That's your own for the baby, I have brought only a few. This big one is for the older one.
A-J teroza e dey dey? 


$\begin{array}{ll}\text { Regular variety } & \text { trouser dem dey dey? } \\ \text { Free trans } & \text { Are there trousers too? } \\ \text { J-A } & \text { na you for look am noh, terozah no day for dis one, na up dem } \\ \text { Regular variety } & \text { na for you for look am noh, trouser dem no dey for dis one, na up dem } \\ \text { Free trans } & \text { It is for you to search through, these ones are only tops, there are no trousers } \\ \text { J-A } & \text { terozah dem dey na for that one for inside da big big bag } \\ \text { Free trans } & \text { Trousers are found inside the other very big bag }\end{array}$

There is not such a huge difference in both varieties of CPE as can be noticed in the excerpt above. However, Jael still tweaks her language to align with that of someone she would like to connect with, to earn her trust and friendship which may encourage the later to purchase her goods. Language in Lower Fungom is a symbolic tool used to situate oneself within a social group- a family, ethnicity, tribe, culture. In order words, language use in Lower Fungom is largely indexical (Silverstein, 2003; Di Carlo, Good, and Ojong Diba (2019); they are principally used as representations of the speaker (see, e.g., Le Page and Tabouret Keller, 1985 and Irvine and Gal 2000). Successful communication is obtained by producing signs via these languages whose associated indexical layer of meaning will be decoded by the other interactants in appropriate ways as they share metapragmatic knowledge. Individuals choose a particular language or even tweak a particular language like CPE, like Jael to for metapragmatic reasons.

The excerpt above is in line with the thoughts of Franceschini (1998), who asserts that "language serves to differentiate the speaker from others and by marking the speaker's belonging to a certain group by means of a similar use of language." The converging use of language, to her, creates confidence and cohesion, whereas divergent use of language tends to be ambivalent and dissociative and is easily associated with either 'personal' or 'foreign'. She maintains that speakers know how to use these codes and they are well aware of which values are transported by means of these codes.

\section{Exhibit 2}

For further illustration of these fact-indexical ideologies of languages in Lower Fungom, consider this other interaction from Kulani, another consultant from Buu, in Lower Fungom, who was walking from his native village Abar to a meeting holding in another village of Lower Fungom- Fang. During his walk, he wore a lavalier microphone and a recorder. His conversations were recorded in a three-hour thirty-minute-long audio recording and the conversations were transcribed and translated in English in an ELAN file a couple of days later. From the recordings, I observed that, while still in Abar, Kulani used CPE and Abar to discuss with people he met along his journey but as soon as he reached Buu and met its indigenes, he began using Buu. (This was corroborated by Kulani himself as we analyzed the recording in ELAN). Kulani went to his allegedly very good friend Pa Joseph's house, he greeted him in Buu and his wife in Mundabli as Pa Joseph was from Buu while his wife was from Mundabli. Kulani conversed with Pa Joseph in Buu until he took offense at one of Pa Joseph's statements. From then on, Kulani began speaking in Abar (his L1) with Pa Joseph until he left Buu. Pa Joseph found this apparently ordinary act as barbaric; however, he kept speaking in Buu to Kulani whenever they spoke. Kulani persisted with his use of Abar in Buu and switched to Buu to talk to other Buu indigenes such as his reportedly best friend Jumia.

Worthy of note, Pa Joseph shared a similar repertoire with Kulani; Kulani spoke all the languages of Lower Fungom (see Ojong Diba, 2020). Pa Joseph reportedly spoke Buu, Fang, CPE, Mundabli, and Abar. This means that both could speak any of the languages $\mathrm{Pa}$ Joseph spoke with no impediment in communication. In addition, Pa Joseph reportedly spoke Abar like a native speaker. He reported that he had learned it from Abar girls who got married in Buu. He also asserted that whenever he met someone from Abar, he spoke Abar with that person, but in the recording and whenever I observed this pair, Pa Joseph did not speak this language with Kulani. In a sociolinguistic interview with Pa Joseph, he stated that although Kulani's father came from Abar parents, and was also born in Abar, he grew up in Buu. Kulani himself was born in Buu; he, just like his father, grew up in Buu before he was later taken to Abar. Pa Joseph consequently considered Kulani as an indigene of Buu, just like himself. When I asked him why he always spoke in Buu with Kulani and not in Abar, Pa Joseph responded by saying that one could not meet their child and choose to use another man's language with them.

Pa Joseph learned Mundabli in Mundabli as he used to go there for a dance, but it was his wife who had perfected his knowledge of this language. He, however, did not use Mundabli with Kulani, although Kulani's mother was from Mundabli and he also knew that Kulo had native fluency in this language. So, when Kulani decided to use another language with Pa Joseph, bearing all this in his mind, it was an absolutely conscious decision that marked sourness and distancing. This type of interaction is what one would typically find in Lower Fungom. It exemplifies fundamental traits of Lower Fungom metapragmatic knowledge. The kind of knowledge that is required of foreign experts desiring to positively impact the community.

In the transcription provided below, the original language is given first, with a free English translation given for each line. The three different languages that are used are represented through different typefaces: Buu is in italics, Mundabli in bold, and Abar both in italics and underlined. The major participants are Pa Joseph (PJ), his wife (PJW), and Kulani (K). [Scene One: In the Village of Buu] 
$\mathrm{K}$ to PJ: Pa Jo! ayeneh eyike hea yike bene Santo ye bene

"Pa Jo, how are you, you are eating. What are you eating there?"

ah! ben dia ben fwom mena "Ah! you people have cooked palm nut?"

PJ to K: a f"om be amerika ฤyike "It is American palm nut that I am eating"

$\mathrm{K}$ to PJ: la kana de jwom ba amerika. amerika wa? "Do I lack American palm nuts? What is

American nuts?"

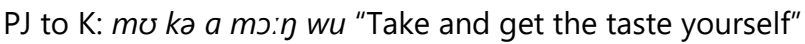

$\mathrm{K}$ to PJ: ay! dzon yen "No! Thank you [sarcastic]"

PJW to K: ben tsi li a t $\int \mathbf{I n}$ ? "Did you sleep well there?"

[Kulani is distracted and does not respond, so pa Jo's wife continues addressing him]

ben nia nu a tfi t $f i a ?$ "Will you remain standing?"

$K$ to PJW: ben feziebe nemsijo ben $\mathbf{t} \boldsymbol{\int i}$ ne ngoko noh "If you say there's something, bring it

... then let me sit"

PJW to K: ay! mbu t $\int \mathbf{i}$ mbu "No! I just asked"

PJ to K: nam fe dzuo ayena kemu "Sit down and eat child"

a tem eke ndie eyika nemfe zohfoh "You are boasting with whom that you can feed yourself?" nam fa dzo-fa ke a ben yi wan "Sit down and eat"

[Pa Joseph is actually shouting at Kulani, asking him to sit down and eat, and for the first time since reaching the village, Kulani completely stops speaking Buu and speaks only Abar, while Pa Joshua maintains his use of Buu.]

$\mathrm{K}$ to PJ: ke lewou lela malaya "Stop troubling me eh"

Scene 2: The Palace in Buu. [Kulani and Pa Joseph enter the chief's house in the village of Buu. Kulani sits down and Pa Joseph remains standing. Kulani then calls on him teasingly.]

K to J: mboh koh mban Pa Jo but ngan "I want to greet Pa Jo but he won't have it"

$\mathrm{J}-\mathrm{K}$ : aleteh nuo gba ... tsang kawe le ishi idungeh

Are you even a person? ... I feel like you are a wild animal living in a forest.

The languages Kulani used in this conversation are not his first languages per se. His father spoke Abar and his mother Mundabli, but he was born and bred in Buu. As such, as noted above, Pa Joseph asserted that Kulani was a son of Buu; they were a family, and Kulani was thus expected to linguistically accommodate to Pa Joseph. According to the culture shared by Kulani, Pa Joseph, and his wife (who is from Mundabli), it was expected that a junior family member should accommodate a senior person's primary linguistic identity. That is why Kulani, in the initial part of the interaction, carefully chose the languages for his two interlocutorshe did not use Mundabli with Pa Joseph, neither did he use Buu with Pa Joshua's wife. Kulani only switched to his primary language, Abar, when the conversation with $\mathrm{Pa}$ Joseph became more aggressive, probably because the older participant was insisting on "thrilling" him with something that he thought was precious and hard to come by. Notice (the end of the excerpt) that the older participant finds the seemingly simple linguistic act performed by Kulani as barbaric. Important generalizations regarding local metapragmatic practices can be derived from both exhibits one and two. For my Ph.D. study from which this paper is extracted, I worked with twenty-three consultants. The sociolinguistic interviews conducted with all twenty-three participants revealed that by using a given local vernacular with other speakers, the main goal of the speaker is to induce in the latter a feeling of trust, unity, and friendship. As we will show later, calling this phenomenon 'solidarity' would mean oversimplifying the matter and leaving untapped its scientific value. Using CPE or English in Lower Fungom would not yield the same results; these languages rather express difference, foreignness, educated all of which signal detachment. This is the reason why in this locality, CPE is reserved to be used only with strangers. It is the very last resort for many; even when an interlocutor cannot speak the language of the speaker, 
it is highly likely that they will choose another language of Lower Fungom in which they both have competence even if none of them is related by blood to a speaker of that language.

Development means shared powers cannot happen when the contact language is a language that inspires distrust, foreignness, and detachment. It cannot be realized by using a language that fails to engage the community. This study argues that the language that will engage this community and sustain prolonged interaction is one that denotes convergence. As such, for sustainable development to be extended to a rural linguistically diverse community such as Lower Fungom, the linguistic factor is indispensable. In that vein, the linguistic factor takes a breath in the collaboration between the indigenes of the region and the foreign experts since it is their language, and they have mastery of the language and the language ideologies of the area. Shared power between the foreign experts and local community in this manner is the only scaffold to sustainable development to be extended to this rural community.

\section{Exhibit 3}

\section{Data from observation- field notes}

While I lived in Lower Fungom, on a day I was not planning any conscious form of ethnographic observation, this interesting observation, and a subsequent casual interview were made. I was visited in my home by a young lady in her early 20 s and we decided to sit outside of the house to converse. While we were at it, a nurse who worked the lone medical center of Lower Fungom walked past my house and when he saw us outside, he walked towards us and then asked my visitor why she had not been stopping by at the hospital to finish the injections she was taking. The nurse did not disclose what she needed the injections for but was strict in telling her that it was imperative that she completed her treatment. When the nurse left, my visitor of her own volition started telling me that she did not feel like taking any more injections for something she could treat with some home remedy like cloves, water, and salt solution. Then she went further to tell me that the doctor had told her that she had gonorrhea.

To the best of my knowledge, I know that no one who understands clearly that gonorrhea is a sexually transmitted disease and knows the stigma that comes along with such a disease in this part of Africa will voluntarily spew it out there. In addition, my visitor did not know the gravity of the situation, hence her staying away from the hospital contrary to the doctor's prescriptions and advice. I asked her if the doctor had explained to her what the disease was, and she responded in the affirmative. Then I went ahead to ask her what she understood by all that the doctor had said. As a matter of fact, she did not retain much, and worst of all, she did not believe the doctor.

The doctor and nurses in Lower Fungom were foreigners trained by the government and sent there on a mission; they did not speak the languages of Lower Fungom. The medical personnel who came to the region intermittently also were strangers to the region. Just like the resident doctor and nurses, they would speak to the indigenes in English or in Cameroonian Pidgin English.

The problem is that these languages express notions that are too far removed from the realities of the people of Lower Fungom. These people may have a level of understanding of the most spoken lingua franca in Cameroon (Neba et al, 2006), but this language together with the foreign experts would not inspire trust and belief. It most definitely would not engage the people of Lower Fungom no matter how grave the situation was or how genuine and resolved the experts were.

\section{Sustainable development in Lower Fungom}

This paper defines development simply as advancement or amelioration. It is also considered as shared powers and the active participation of the people, as citizens in politics and civic life. The indigenes of Lower Fungom, like others in other rural regions, are dynamic, ingenious, untiring, and receptive to development. Development after all has a universal appeal; even people in remote rural areas such as Lower Fungom would certainly desire the betterment of their livelihood. The reason why they are yet to experience steady and continuous improvements in their livelihood, why development efforts have been thwarted right in their infancy in this region could be termed the "language barrier". The language barrier here is not only an impediment as far as communication is concerned because like the term itself says, but it also becomes a literal barrier between foreign experts and the indigenes. The use of CPE and Cameroonian English constructs a barrier of distrust, unfriendliness, disunity, foreignness, and arduousness in the minds of inhabitants of this region.

If any initiative (health, agriculture, academic, social, political) does not take root in the local culture, then it is destined to last only until the last foreign expert has left. Initiatives geared towards the sustainable advancement of the livelihood of the people of Lower Fungom cannot entirely be alien; they should be lodged in the ideologies of the people; in something, they know already and can easily make sense of. It will be a great opportunity to mix external knowledge and foreign knowledge as well as is the contact language with the languages of the target population, instead of further colonizing minority communities by imposing foreign knowledge and foreign linguistic ideologies on them. For this mélange to be achieved, development efforts must consist of trained collaborators acting as liaisons between the foreign experts and the local community. 
Sustainable development can be realized in rural Lower Fungom only if foreign experts target the lived realities of this community, rather than operating from an "I know all" standpoint with odd linguistic behavior. Lower Fungom comprises thirteen distinct villages with each claiming to speak its own language. Collaboration between foreign experts and representatives of each of these villages in every endearvour is a must for sustainable development. What would certainly resonate much more with community members is what their representatives bearing their ideologies and culture in mind will communicate to them.

\section{Conclusion}

In Lower Fungom, language use is primarily symbolic, representative, indexical; the indigenes believe that a code choice indexes a speaker's membership in a particular population. A code being indexical tends to affiliate the speaker to a given group, albeit without specific moral, personal, or overall essentialist features. This is otherwise known as relational identification, a construct that calls on the relationship one has with a given person or group. The role of each language is fixed, identifying the speaker with a particular village. CPE or English does not index any of the villages of Lower Fungom. As such, it does not suggest togetherness and unity. With the use of CPE or English foreign experts represent themselves not as part of the Lower Fungom community but rather as foreigners, as some sort of imperialists. Data for this study suggests that foreign experts cannot ignore the need for the conscious use of the native language of each village for the transmission of knowledge in linguistically diverse communities and be successful at their objectives. For a scheme as large as the global pursuit of sustainable development, it boils down to the minute socio-cultural details peculiar to each rural community. In rural communities, communication is basically oral as most of the indigenes are uneducated. Consequently, people would act upon what they retain during consultations. If this is too far removed from their realities or it is in a language wherein, they cannot have mental imagery, a language that does not stimulate trust and togetherness, but rather detachment, the information would be momentary in their brains. It is essential for rural communities too to experience development. This study puts forward that use of the languages of Lower Fungom, each for its particular village, although unstandardized, otherwise known as under-resourced and collaboration between members of the rural communities and foreign experts is the key to bringing development to rural regions and rendering it sustainable. A foreign language such as $\mathrm{CPE}$, or worst still Cameroonian English will not only trigger distrust, distance, and foreignness, but it would also seem imperialistic and re-colonizing. Data for this study does not only showcase the dedicatedness of the people of Lower Fungom in using languages for indexical purposes but it also highlights the multilingual nature of the region. A plan for sustainable development in multilingual Lower Fungom should therefore have multilingualism- the kind of multilingualism practiced in the area as a scaffold, not a language of wider communication such as CPE or English.

Funding: This research received no external funding

Acknowledgments: I am most grateful to my mentor Pierpaolo Di Carlo for his input in this paper and to my friend and colleague Dr. Kougang Paule Marie, who squeezed out time from her tight schedule to read through this paper.

Conflicts of Interest: The author declares no conflict of interest.

\section{References}

[1] Angiachi E. A. (2013). Rural multilingualism in the Northwest Region of Cameroon: the case of Lower Fungom. Buea: University of Buea MA thesis. URL http://buffalo.edu/ jcgood/EseneAgwara-2013-RuralMultilingualism.pdf

[2] Atechi, S. (2011). "Pidgin English in Cameroon: To teach or not to teach". In international Journal of English Language Studies (IJLS), Vol 5 (1) 53-66.

[3] Di Carlo, P \& Good, J. (2016). What are we trying to preserve? Diversity, change, and ideology at the edge of the Cameroonian Grassfields. In P. Austin \& J. Sallabank (Eds.). Endangered languages: Beliefs and ideologies in language documentation. Oxford and New york: Oxford University Press. 229-262

[4] Di Carlo, P. \& Pizziolo, G. (2012). Spatial reasoning and GIS in linguistic prehistory. Two case studies from Lower Fungom (Northwest Cameroon). Language dynamics and change, 2 (2), 150-183.

[5] Di Carlo, P. (2016). Multilingualism, affiliation, and spiritual insecurity. From phenomena to processes in language documentation. In M. Seyfeddinipur (Ed.). African language documentation new data, methods, and approaches. Language documentation \& conservation special publication 10:71-104.Eberhard, David M., Gary F. Simons, and Charles D. Fennig (eds.). 2020. Ethnologue: Languages of the World. Twentythird edition. Dallas, Texas:SIL International. Online version: http://www.ethnologue.com.

[6] Irvine, J. T. and S. Gal. (2000). Language ideology and linguistic differentiation. In P. V. Kroskrity (Ed.), Regimes of language: Ideologies, polities, and identities, 35-84. Santa Fe, NM: School of American Research Press.

[7] Le Page, R. B. and A. Tabouret-Keller. (1985). Acts of identity: Creole-based approaches to language and ethnicity. Cambridge: Cambridge University Press

[8] Lüpke, Friederike. (2009). At the margin—African endangered languages in the context of global endangerment discourses. African Research and Documentation 109. 15- 41.

[9] Lüpke, F. (2016). Uncovering small-Scale multilingualism. Critical multilingualism studies 4.2, 35-74.

[10] Ojong Diba, R. A. (2019). The sociolinguistic dynamics of rural multilingualism in Africa. Case Study: Lower Fungom. Unpublished PhD thesis. University of Buea.

[11] Ojong Diba, R. A. (2019) Nuances in Language Use in Multilingual Settings Code-Switching or Code Regimentation in Lower Fungom?. In Lexington Books. USA. 
[12] Stallcup, Kenneth. (1980). La géographie linguistique des Grassfields. In Larry Hyman \& Jan Voorhoeve Jan (eds.), L'expansion Bantoue: Actes du Colloque International du CNRS, Viviers (France) 4-16 avril 1977. Volume I: Les Classes Nominaux dans le Bantou des Grassfields, 43-57. Paris: SELAF.

[13] Silverstein, Michael. (2003). Indexical order and the dialectics of sociolinguistic life. Language \& Communication 23.193-229.

[14] Worldometers.info. (2020). www.Worldometers.info. Elaboration of data by United Nations, Department of Economic and Social Affairs, Population Division. 